\title{
REFLEXÕES SOBRE AS POLIITICAS EDUCACIONAIS VOLTADAS PARA TODOS AQUELES QUE NÃO TIVERAM ACESSO À EDUCAÇÃO NA IDADE PRÓPRIA
}

Fernanda Reis

Taís Aparecida de Moura

\begin{abstract}
RESUMO
Este texto objetiva tecer algumas reflexões sobre as políticas educacionais direcionadas aos sujeitos que não tiveram acesso à educação na idade própria, a saber, alunos a alunas do EJA. Nessa direção, de cunho teórico e bibliográfico, o trabalho esta estruturado em dois tópicos. O primeiro trata do direito à educação, em que esta questão é situada no bojo dos principais marcos legais instituídos no mundo e no Brasil como algo fundamental. Na sequência, debate-se, mais precisamente, sobre as políticas públicas brasileiras pensadas para a clientela da EJA, e ressalta-se, ao mesmo tempo, o quanto elas são reflexo de discussões internacionais e nacionais com o foco na educação, especialmente no final do século XX. Pôde-se inferir que a preocupação com a EJA estava diretamente relacionada com os níveis de alfabetização de jovens e adultos no país, sendo que o quadro de analfabetismo permanece alarmante. Portanto, entendese que é necessário ampliar o sentido das políticas públicas da EJA na atualidade, no sentido de avançar quanto a propostas que de fato possibilitem a igualdade na educação.
\end{abstract}

Palavras- chave: Direito à educação. Políticas Públicas. Educação de Jovens e Adultos (EJA).

\section{Introdução}

Em um mundo em que as diferenças sociais são latentes, o lugar da educação como um direito social de suma importância, por meio dos dispositivos legais, é sem dúvida uma grande conquista alcançada. Por isso, as políticas educacionais desenvolvidas no Brasil ao longo da história têm procurado sanar diversas demandas populacionais, sendo elaboradas e reelaboradas de acordo com as necessidades de cada época. Entretanto, legislar em um contexto tão singular como o brasileiro nem sempre é uma tarefa fácil, já que existem muitos obstáculos, divergências e dificuldades, sempre presentes quando se almeja construir uma política igualitária.

Frente a estas considerações, o presente trabalho ${ }^{1}$, de natureza teórica e bibliográfica, tem por objetivo refletir acerca das políticas públicas voltadas para todos

\footnotetext{
${ }^{1}$ Este trabalho trata-se de um recorte de uma pesquisa mais ampla realizada por Moura (2013) em seu trabalho de conclusão do curso de Especialização Lato Sensu em Ética, Valores e Cidadania na Escola pela USP em parceria com a UNIVESP acerca das questões de leitura, escrita e cidadania na Educação de Jovens e Adultos. Também consiste como fundamento deste artigo o conjunto de discussões feitas na disciplina do Mestrado em Educação Escolar de Fundamentos e Gestão da Política Educacional, cursada na UNESP Campus de Araraquara no $2^{\circ}$ semestre de 2013, na qual as autoras realizaram um seminário
} 
aqueles que não tiveram acesso à educação na idade própria, isto é, os alunos e alunas da Educação de Jovens e Adultos (EJA). Para isso, em um primeiro momento, esclarece-se a respeito do direito a educação, ao fazer apontamos importante para se entender como esta questão se insere nos marcos legais instituídos no decorrer da história mundial e no Brasil. Finalmente, em um segundo instante, discute-se acerca das políticas implementadas para ao EJA no país, no sentido de ressaltar as influências dos debates tanto no domínio internacional, quanto nacional nas formulações políticasnormativas brasileiras.

\section{O direito a educação como ponto de partida}

Nos últimos tempos, debater acerca de uma educação que de fato contemple todos os indivíduos tem se tornado cada vez mais urgente em nossa sociedade. Nesse cenário, as políticas públicas educacionais surgem como principais alternativas para que os direitos de todos sejam assegurados e ganham, assim, relevância enquanto instrumentos que podem auxiliar na redução das desigualdades existentes.

Ao desdobrar um pouco mais a este respeito, um breve resgate histórico permite lembrar que o reconhecimento da instrução como um direito tem início no século XVIII com a formação do Estado de direito, engendrado no interior das lutas sociais. De fato, a educação foi incorporada como um dos direitos sociais para a cidadania de forma gradual a contraditória, uma vez que antes da idade moderna esse direito ao ensino sequer existia como algo a ser considerado (BRASIL, 2013; BOBBIO, 1992; HORTA, 1998).

Todavia, a educação como direito social se estabelece em esfera internacional após a $2^{\circ}$ Guerra Mundial, quando finalmente a $\mathrm{ONU}^{2}$ regulariza questões pertinentes aos direitos humanos (BRASIL, 2013). Como assinala Horta (1998, p. 7), a partir deste período “[...] assiste-se a uma considerável democratização do ensino e um aumento da duração da escolaridade obrigatória [...]”. Logo, dentre os muitos dispositivos legais que passam a versar sobre o direito a educação destaca-se a Declaração Universal dos Direitos Humanos, proclamada em 1948, pois em seu artigo 26 o amparo a esta determinação se encontra explicitado:

com ênfase nas políticas públicas que delineiam a Educação Básica no Brasil. Tal disciplina foi orientada pelos professores Sebastião de Souza Lemes, Ricardo Ribeiro e professora Marta Leandro da Silva.

${ }^{2}$ Organização das Nações Unidas a nível internacional fundada no ano de 1945. Composta por governos do mundo todo, tal Organização trabalha no intuito de auxiliar quanto a diversas questões como a segurança, o desenvolvimento, os direitos humanos e paz mundial, dentre outros aspectos. 
Artigo 26-1. Toda pessoa tem direito à instrução. A instrução será gratuita, pelo menos nos graus elementares e fundamentais. A instrução elementar será obrigatória [...].

2. A instrução será orientada no sentido do pleno desenvolvimento da personalidade humana e do fortalecimento do respeito pelos direitos humanos e pelas liberdades fundamentais. A instrução promoverá a compreensão, a tolerância e a amizade entre todas as nações e grupos raciais ou religiosos, e coadjuvará as atividades das Nações Unidas em prol da manutenção da paz (NAÇÕES UNIDAS, 1948).

Com efeito, vê-se que o documento em questão possui uma amplitude muito grande em termos de igualdade e de direitos educacionais, sobretudo ao considerar que a sociedade de modo geral também se incumbe da educação, já que o desenvolvimento humano seria o objetivo maior, o ponto principal a ser alcançado. Para Bobbio (1992), a Declaração Universal dos Direitos do Homem significa a confirmação mediante o qual se pode fundamentar de forma humana um sistema de valores, sendo tal confirmação exatamente o assentimento geral da legitimidade desse documento.

Nesse bojo, no caso do Brasil o entendimento da educação como um direito do indivíduo nem sempre esteve presente em terras tupiniquins (BRASIL, 2013). Dessa maneira, durante muito tempo a educação brasileira esteve marcada pelos preceitos jesuítas, em que pressupostos europeus advindos de uma cultura e de uma religião distinta se fizeram presentes no cotidiano das populações nativas que aqui habitavam. Grosso modo, no período colonial poucos indivíduos tiveram, de verdade, acesso a educação, pois como adverte Romanelli (1986) a escola se destinava a uma classe dominante, isto é, a filhos homens, não primogênitos, dos senhores de engenho.

Com o passar do tempo, apesar das Constituições de 1824 e de 1891 propagarem a educação como um direito de todos, sabe-se que este privilégio ainda se reduzia a uma minoria, as quais política e socialmente não dispunham de muita representatividade. Do mesmo modo, da Constituição de 1934 até a de 1967 a concepção da tida "educação básica" se resumiu ao ensino primário, com gratuidade e obrigatoriedade, que também agregava jovens e adultos. Assim, nos dizeres destes instrumentos legais, mais uma vez, os direitos sociais e culturais praticamente inexistiam (BRASIL, 2013; FREITAS, 2008).

No entanto, após a instituição da Constituição Federal em 5 de outubro de 1988 o país começou a caminhar rumo a importantes mudanças a nível de democracia, uma vez que tal instrumento normativo passa a representar um marco político no sentido de respaldar os cidadãos e cidadãs quanto aos seus direitos fundamentais. Nessa 
perspectiva, a educação se encontra positivamente contemplada, reconhecida, desse modo, como um direito social, o que certamente significou um grande avanço comparado com a legislação vigente até o período em questão. Isso fica muito claro nos dizeres de tal disposição quando no corpo da lei a preocupação com a educação se amplia, como vê-se a seguir:

Art. 205. A educação, direito de todos e dever do Estado e da família, será promovida e incentivada com a colaboração da sociedade, visando ao pleno desenvolvimento da pessoa, seu preparo para o exercício da cidadania e sua qualificação para o trabalho (BRASIL, 1988).

Em uma linha semelhante a que embasou a Constituição Federal em 1988, na década de 1990, o tom maior das elaborações políticas para a educação no Brasil foi a preocupação com a cidadania. Destarte, como parte integrante do processo de democratização do país, em que o acesso à educação surge gradativamente como uma demanda imperativa dentro da sociedade brasileira, em 20 de dezembro de 1996 é promulgada a nova Lei de Diretrizes e Bases da Educação Nacional (LDBEN), Lei Federal n 9.394. De acordo com Freitas (2008), nesta lei emerge uma ideia de educação ainda mais expandida, que ocorre não só na família como também em instâncias não formais, a saber, no seio da sociedade civil, no decurso do convívio humano, nos movimentos sociais, nas manifestações culturais, e nas instituições de ensino e pesquisa.

Dando prosseguimento, outra questão que chama atenção no marco legal em discussão se trata da obrigatoriedade do ensino fundamental, que nos dizeres do título II, artigo $5^{\circ}$ se torna direito público subjetivo (BRASIL, 1996). Nesses termos, ao explicar à origem desta expressão, na célebre obra intitulada A era dos direitos, Norberto Bobbio (1992) mostra que os direitos subjetivos na verdade qualificam o Estado de direito, ao passo que neste último os sujeitos usufruem dos seus direitos privados, bem como dos seus direitos públicos. Logo, nessa ótica o direito subjetivo implica que qualquer cidadão que não consiga cursar esta modalidade de ensino pode acionar judicialmente o Estado para cobrar o direito à vaga garantida por lei.

Em uma análise mais apurada a respeito deste artigo da LDBEN, apesar de reconhecer os progressos relevantes desta lei, Freitas (2008) faz a crítica à redução assumida pela educação básica, já que a prioridade, o básico obrigatório, seria o ensino fundamental. Para a autora, o enfoque nesta etapa de ensino é justificado pelos diagnósticos negativos quanto à média de anos de escolarização da população brasileira 
atrelado aos elevados níveis de analfabetismo, a falta de equidade social, dentre outros fatores.

Devido às muitas transformações sociais ao longo dos anos, na atual conjuntura política, a LDBEN tem passado por reestruturações consideráveis. Com efeito, convém aclarar que por intermédio da redação dada pela Lei $n^{\circ} 12.796$, no dia 4 de maio de 2013, alguns pontos desta política educacional foram modificados. Dessa maneira, dentre as muitas alterações promovidas esta lei, que tem como objetivo principal instituir a obrigatoriedade de matrícula para crianças a partir dos 4 anos de idade na Educação Infantil, estende a obrigatoriedade do ensino a toda a educação básica. Sancionada, no título III, o qual trata do direito de educar ficou definido por tal normatização que:

Art. $4^{\circ}$. O dever do Estado com a educação escolar pública será efetivado mediante a garantia de:

I - Educação básica obrigatória e gratuita dos quatro aos dezessete anos de idade, organizada da seguinte forma:

a) pré-escola,

b) ensino fundamental,

c) ensino médio, [...] (BRASIL, 1996).

Ao mesmo tempo, ratifica-se o direito ao ensino como direito público subjetivo:

Art. $5^{\circ}$. O acesso e educação básica obrigatória é direito público subjetivo, podendo qualquer cidadão, grupo de cidadãos, associação comunitária, organização sindical, entidade de classe ou outra legalmente constituída e, ainda, o Ministério Público, acionar o poder público para exigi-lo. [...] (BRASIL, 1996).

Portanto, ao considerar que o direito a educação seria algo já reconhecido mediante normatizações internacionais e a legislação brasileira, faz-se essencial concentrar esforços para que de fato ele seja garantido. Isso significa dizer que essas políticas públicas destinadas à educação só ganham significado e efetividade se a sociedade de modo geral cobrar seus direitos, participar de maneira mais expressiva das decisões tomadas em âmbitos políticos, como na escolha das necessidades de uma determinada população, de forma justa e igualitária. É exatamente no contexto da luta por um sistema educacional que contemple a todos, sem nenhuma forma de distinção, preconceito e exclusão que também nasce à realidade vivenciada por todos os aqueles que não tiveram acesso à educação na idade própria, como é o caso da Educação de Jovens e Adultos (EJA), que veremos a seguir. 


\section{Fatos e Atos das políticas públicas da EJA no Brasil}

A discussão de políticas públicas voltadas a EJA, em nosso país, sempre esteve atrelada com a questão da alfabetização e ocorreu no transcorrer do século XX, acompanhada conforme Di Pierro, Vóvio e Andrade (2008) apontam por uma constituição tardia do sistema público de ensino. Entretanto, Haddad e Di Pierro (2000) sinalizam que a ação educativa junto a adolescentes e adultos no Brasil não é nova, partindo do pressuposto que desde o período colonial os jesuítas exercitavam o ensino com um caráter missionário para grande parte dos adultos.

Porém a história da educação do nosso país demonstrou que com a desorganização do sistema de ensino por meio da expulsão dos jesuítas em 1759, de acordo com Haddad e Di Pierro (2000) foi somente no período Imperial, com a Constituição de 1824, que se garantiu o direito a instrução primária e gratuita para todos os cidadãos. No entanto, este direito não passou de uma intenção legal.

Assim, apenas no período da Primeira República (1889-1930) houve algumas reformas educacionais, das quais se preocuparam com o estado precário do ensino básico. Isso porque segundo dados apontados na pesquisa de Haddad e Di Pierro (2000, p.110) “o censo de 1920, realizado após o estabelecimento da República no país, indicou que $72 \%$ da população acima de cinco anos permanecia analfabeta". E, infelizmente verificou-se que estes dados não sofreram grandes alterações, tendo em vista, que segundo Di Pierro, Vóvio e Andrade (2008, p.21) "até 1950 mais da metade da população brasileira era analfabeta, o que a mantinha excluída da vida política, pois o voto the era vetado". Assim:

Foi somente ao final da década de 1940 que a educação de adultos veio a se firmar como um problema de política nacional (...). O Plano Nacional de Educação de responsabilidade da União, previsto pela Constituição de 1934, deveria incluir entre suas normas o ensino primário integral gratuito e de frequência obrigatória. Esse ensino deveria ser extensivo aos adultos. Pela primeira vez a educação de jovens e adultos era reconhecida e recebia um tratamento particular. (HADDAD; DI PIERRO, 2000, p.110)

Neste contexto, cabe mencionar fatos transcorridos no âmbito das relações internacionais, dos quais segundo Haddad e Di Pierro (2000) ampliaram o movimento em prol de uma Educação de Jovens e Adultos, que tiveram reflexos no Brasil. A saber, por exemplo, a criação da Organização das Nações Unidas para a Educação, a Ciência e a Cultura (UNESCO) que volta suas preocupações à educação e a desigualdade social. 
Entretanto, é com a criação do Serviço de Educação de Adultos (SEA) em 1947 e mediante a Campanha de Educação de Adolescentes e Adultos (CEAA) que se estendeu até o final da década de 1950, que o debate entorno da EJA passou a ganhar maior visibilidade no país.

Contudo, conforme Di Pierro, Andrade e Vóvio (2008) assinalaram mesmo com a criação de outras campanhas, como a Campanha Nacional de Educação Rural de 1952 e a Campanha Nacional de Erradicação do Analfabetismo em 1958, houve poucos resultados efetivos na qualidade da EJA, isso por que:

Inúmeras críticas foram dirigidas às campanhas, devido ao caráter superficial do aprendizado que se efetivava num curto período de tempo e a inadequação dos programas, modelos e materiais pedagógicos, que não consideravam as especificidades do adulto e a diversidade regional. (DI PIERRO, VÓVIO; ANDRADE, 2008, p. 21)

De fato houve avanços, mas as medidas paliativas voltadas para todos aqueles que não tiveram acesso à educação na idade própria foram limitadas e contidas, considerando que:

Os esforços empreendidos durante as décadas de 1940 e 1950 fizeram cair os índices de analfabetismo das pessoas acima de cinco anos de idade para 46,7\% no ano de 1960 . Os níveis de escolarização da população brasileira permaneciam, no entanto, em patamares reduzidos quando comparadas à média dos países em primeiro mundo e mesmo de vários dos vizinhos latino-americanos. (HADDAD; DI PIERRO, 2000, p. 111)

Portanto, se reitera que mesmo lentamente observou-se um movimento em favor da educação, afinal, as campanhas de alfabetização estenderam as oportunidades de escolarização aos jovens e adultos. Neste cenário, o início da década de 60 até os anos de 1964 foi um período de luzes para a EJA, de acordo com Pierro (2005, p. 1117), porque "os movimentos de educação e de cultura populares ligados a organizações sociais, à Igreja Católica e ao governo desenvolveram experiências de alfabetização de adultos".

Assim, verificou-se um período de efervescência política no Brasil e no âmbito da educação experimentaram-se novas práticas de alfabetização, das quais é possível citar os exemplos de:

Movimento de Educação de Base, da Conferência Nacional dos Bispos do Brasil, estabelecido em 1961, com o patrocínio do governo federal; o Movimento de Cultura Popular do Recife, a partir de 1961; 
a Campanha de Pé no Chão Também se Aprende a Ler, da Secretaria Municipal de Educação de Natal; e os Centros Populares de Cultura, órgãos culturais da União Nacional dos Estudantes (UNE). (DI PIERRO, VÓVIO; ANDRADE, 2008, p.22)

Entretanto, as diretrizes que se encaminharam em direção de um Plano Nacional de Alfabetização foram interrompidas com o golpe militar em 1964 e, por consequência, a repressão se abateu sobre os movimentos de educação populares, por exemplo, encerrou-se o Programa Nacional de Alfabetização de Adultos, cujo planejamento incorporava as orientações de Paulo Freire. Os movimentos da educação e cultura populares foram reprimidos, seus dirigentes perseguidos e os ideais censurados, pois a repressão foi a resposta do Estado autoritário as ações de natureza política que contrariavam os interesses impostos pelo golpe militar. (HADDAD; DI PIERRO, 2000).

No período militar o Governo Federal organizou o Movimento Brasileiro de Alfabetização (MOBRAL), no qual tratou a respeito da escolarização de jovens e adultos analfabetos em várias localidades do Brasil. Segundo Pierro, Joia e Ribeiro (2001) tal programa contribuiu para legitimar a nova ordem política implantada no país, isto é, colaborou na manutenção da coesão social, mas ao mesmo tempo, significou avanços no debate acerca da escolarização de jovens e adultos.

Ainda no período de ditadura militar consolidou-se juridicamente uma alteração na primeira Lei de Diretrizes e Bases da Educação Nacional 4.024/61. Nesta nova versão, a LDBEN 5.692 de 11 de agosto de 1971, passou a dispor acerca do ensino voltado aqueles que não haviam realizado ou completado na idade própria a escolaridade obrigatória.

Neste contexto, a política do Ensino Supletivo configurava-se como importante, na medida em que visava de acordo com Haddad e Di Pierro (2000, p.116) "suprir a escolarização regular e promover crescente oferta de educação continuada". Portanto, o capítulo IV da LDBEN de número 5.692/71 dispõe que:

O ensino supletivo terá por finalidade: a) suprir, a escolarização regular para os adolescentes e adultos que não a tenham seguido ou concluído na idade própria; 1) proporcionar, mediante repetida volta à escola, estudos de aperfeiçoamento ou atualização para os que tenham seguido o ensino regular no todo ou em parte. $\mathrm{O}$ ensino supletivo abrangerá cursos e exames a serem organizados nos vários sistemas de acordo com as normas baixadas pelos respectivos Conselhos de Educação. (BRASIL, 1971, Art. 24) 
Contudo, o direito mais amplo a educação básica, só foi estendido efetivamente aos jovens e adultos na Constituição Federal de 1988, porque apesar do Ensino Supletivo desde 1971 ser implantado em todo território nacional, segundo estudiosos da temática como Haddad e Di Pierro (2000) houve uma insuficiência na cobertura do ensino oferecido, na qual era composta por dificuldades de ordem política, administrativa, financeira e pedagógica que limitavam a extensão e a qualidade da EJA.

A história da Educação de Jovens e Adultos no período de redemocratização foi marcada pela extinção do MOBRAL em 1985, quando o processo de abertura política e os debates sociais estavam mais avançados no país. Logo, no período da Nova República no Brasil (início em 1985), o MOBRAL foi substituído pela Fundação Nacional para Educação de Jovens e Adultos (EDUCAR), cujo objetivo principal foi:

[...] assumir a responsabilidade de articular, em conjunto, o subsistema de ensino supletivo, a política nacional de educação de jovens e adultos, cabendo-lhe fomentar o atendimento nas séries iniciais do ensino de $1^{\circ}$ grau, promover a formação e o aperfeiçoamento dos educadores, produzir material didático, supervisionar e avaliar as atividades. (HADDAD; DI PIERRO, 2000, p.120)

Transcorridos alguns anos em 1990 a Fundação Educar foi extinta no governo do presidente Fernando Collor de Mello e, quanto às questões que tangem o financiamento dos programas voltados a EJA, pode-se interpretar que houve uma nova configuração, porque conforme Haddad e Pierro (2000) sinalizaram a transferência direta da responsabilidade pública dos programas de alfabetização de jovens e adultos passou da União para os munícipios.

Cabe lembrar, que a partir da Constituição de 1988 o direito ao voto aos analfabetos foi restituído em caráter facultativo e, neste contexto, mediante as explanações feitas por Di Pierro, Vóvio e Andrade (2008) cabe ressaltar que também foi concedido o direito ao Ensino Fundamental público e gratuito aos jovens e adultos, tendo em vista, que o governo se comprometeu a superar o analfabetismo e a provisão do ensino elementar para todos.

De fato, a preocupação com a superação do analfabetismo é reflexo de discussões recorrentes no âmbito internacional e nacional, pois o ano de 1990 foi declarado pela ONU como o Ano Internacional de Alfabetização. As discussões acerca desta temática de extrema relevância se deram na Conferência Mundial de Educação Para Todos, realizada em Jomtien, na Tailândia, em 1990. 
Para entender a urgência da Educação para Todos, cabe destacar que a situação da Educação Básica no mundo no início de 1990 era preocupante (continua a ser), considerando alguns índices, pois:

ais de 100 milhões de crianças - 60 milhões delas, meninas - sem acesso à escola primária.

ais de 960 milhões de adultos - dois terços deles, mulheres analfabetos, e um número sem estimativa, mas, sem dúvida, crescente de analfabetos funcionais (pessoas que dizem saber ler e escrever, mas cujo manejo da língua escrita é insuficiente para utilizá-la com sentido na vida diária).

- $\quad \mathrm{M}$ ais de um terço dos adultos do mundo à margem das informações e dos conhecimentos elementares necessários para melhorar sua vida e a de seus familiares.

ais de 100 milhões de crianças e incontáveis adultos não conseguem completar a escola primária, e um número indeterminado - mas com certeza alto - consegue concluí-la, mesmo sem ter adquirido os conhecimentos básico que a escola deve garantir. (TORRES, 2001, p.20)

Ao fazer uma breve análise dos dados apontados pela autora percebe-se que se faz necessário às políticas públicas se atentarem a educação, principalmente, daqueles que não concluíram os estudos na idade própria e também aqueles que acabaram constituindo um grupo de analfabetos funcionais, que infelizmente, ficaram à margem da sociedade brasileira. Em outras palavras, apesar do grande crescimento da matrícula escolar em todas as regiões do mundo, o desafio da educação básica para todos, continua em pé. (TORRES, 2001)

Na prática, os debates nesta conferência emergiram muitas políticas públicas no Brasil associadas a leis, diretrizes e decretos. Mazzeu (2009) elucida que as propostas educacionais, de modo geral, foram embasadas pelas recomendações de organismos multilaterais internacionais e regionais, como: Banco Mundial, UNESCO, Fundo das Nações Unidas para a Infância (UNICEF), Comissão Econômica para a América Latina e o Caribe (CEPAL) e o Programa das Nações Unidas para o desenvolvimento (PNUD).

Com a promulgação da LDBEN 9.394/96 constatou-se um recorte em relação à Educação de Jovens e Adultos, sendo que é preciso enfatizar que tal destaque direto ou indiretamente foi fruto dos debates internacionais em relação ao desafio da educação para todos, no qual se definiu que: 
A educação de jovens e adultos será destinada àqueles que não tiveram acesso ou continuidade de estudos no ensino fundamental e médio na idade própria.

$\S 1^{\circ}$. Os sistemas de ensino assegurarão gratuitamente aos jovens e aos adultos, que não puderam efetuar os estudos na idade regular, oportunidades educacionais apropriadas, consideradas as características do alunado, seus interesses, condições de vida e de trabalho, mediante cursos e exames. (BRASIL, 1996, Art. 37.)

Portanto, é neste cenário político que Educação de Jovens e Adultos é convidada de acordo com Di Pierro, Joia e Ribeiro (2001) a reavaliar sua identidade e tradição reelaborando os objetivos de formação política para a cidadania democrática que seus currículos sempre souberam explicitar e que na atual conjuntura os valores éticos, morais e sociais não podem ficar secundarizados.

\section{Considerações finais}

Neste trabalho de natureza teórica e bibliográfica buscou-se refletir acerca das políticas públicas voltadas para todos aqueles que não tiveram acesso à educação na idade própria, isto é, os alunos e alunas da EJA.

Num primeiro momento discutiu-se sobre o direito à educação, tendo em vista, que os apontamentos feitos foram esclarecedores para se compreender que nos marcos legais as políticas educacionais da EJA no Brasil foram se constituindo, por meio de normatizações internacionais e brasileiras.

Ao que se refere, especificamente, a história da constituição das políticas públicas voltadas para todos aqueles que não tiveram acesso à educação na idade própria, constatou-se que a preocupação com a EJA estava fortemente atrelada com os índices do nível de alfabetização de jovens e adultos em nosso país, isso porque, ainda permanecem alarmantes os números de pessoas que são analfabetas ou tidas como analfabetas funcionais.

Diante dessas considerações, verificou-se que é preciso ampliar o sentido das políticas públicas da EJA, afinal, para além da garantia dos direitos já adquiridos no âmbito da educação é preciso que estas leis se efetivem e se concretizem no contexto escolar de forma justa e igualitária, pois o desafio da educação básica para todos é um tema à luz de muitas outras pesquisas na área da educação. 


\section{Referências}

BOBBIO, N. A era dos direitos. Rio de Janeiro: Campus, 1992.

BRASIL. Constituição (1988). Constituição da República Federativa do Brasil. Brasília: Senado Federal, 1988. Disponível em: http://www.planalto.gov.br/ccivil_03/constituicao/constituicaocompilado.htm. Acesso em 12 jan. 2013.

Lei $\mathrm{n}^{\circ}$. 9. 394, de 20 de dezembro de 1996. Estabelece diretrizes e bases da educação nacional. Diário Oficial da República Federativa do Brasil, nº. 248, de 23 de dezembro de 1996.2 Disponível em http://www.planalto.gov.br/ccivil_03/leis/19394.htm. Acesso em 12 jan. 2013.

BRASIL. Secretaria de Direitos Humanos da Presidência da República, Direito à Educação. - Brasília: Coordenação Geral da Educação em SDH/ PR, Direitos Humanos, Secretaria Nacional de Promoção e Defesa dos Direitos Humanos, 2013.

DI PIERRO, M. C. Notas sobre a redefinição da identidade e das políticas públicas de educação de jovens e adultos no Brasil. Educ. Soc., Campinas, vol.26, n.92, p.11151139, especial - Out. 2005.

DI PIERRO, M. C.; JOIA, O.; RIBEIRO, V. M. Visões da educação de jovens e adultos no Brasil. Cadernos Cedes, ano XXI, $\mathrm{n}^{\circ}$ 55, novembro, 2001. Disponível em: $\langle$ http://www.scielo.br/scielo.php?pid=S0101-32622001000300005\&script=sci_arttext $>$. Acesso em: 19 set. 2013.

DI PIERRO, M. C.; VÓVIO, C. L.; ANDRADE, E. R. (Coord.). Alfabetização de jovens e adultos no Brasil: lições da prática. Brasília: UNESCO, 2008.

FREITAS, D. N. T. de. A concepção de educação básica no discurso político-normativo brasileiro. In: FREITAS, D. N. T. de; FEDATTO, N. A. S. da (Orgs.). Educação básica: discursos e práticas político-normativas e interpretativas. Dourados: UFGD, 2008. p. 33-53.

HADDAD, S.; DI PIERRO, M. C. Escolarização de jovens e adultos. Revista Brasileira de Educação, São Paulo, n.14, p.108-130, maio/ago. 2000.

HORTA, J. S. B. Direito à educação e a obrigatoriedade escolar. In: Cadernos de Pesquisa, São Paulo, n. 104, p. 5-34, julho. 1998. Disponível em: http://www.fcc.org.br/pesquisa/publicacoes/cp/arquivos/158.pdf. Acesso em 12 jan. 2013.

MAZZEU, L. T. B. A Política de Formação Docente no Brasil: Fundamentos Teóricos e Epistemológicos. Trabalho apresentado no GT - Estado e Política Educacional, durante a $32^{\mathrm{a}}$ Reunião Anual da ANPEd, realizada em Caxambu, MG, de 4 a 7 de outubro de 2009. Disponível em: <http://www.anped.org.br/reunioes/32ra/arquivos/trabalhos/GT05-5789--Int.pdf>.

Acesso em: 20 mai. 2013. 
MOURA, T. A. Os (entre) laços da leitura, da escrita e da cidadania na Educação de Jovens e Adultos (EJA). Trabalho de Conclusão do curso de Especialização Lato Sensu em Ética, Valores e Cidadania na Escola, USP e UNIVESP, São Carlos, 2013.

NAÇÕES UNIDAS. Declaração Universal dos Direitos Humanos. Brasília: Ministério das Relações Exteriores, Ministério da Justiça, 1948. Disponível em: http://portal.mj.gov.br/sedh/ct/legis intern/ddh bib inter universal.htm. Acesso em 12 jan. 2013.

ROMANELLI, O. O. de. História da educação no brasil (1930-1973). 8. ed. Petrópolis: Vozes, 1986.

TORRES, R. M. A Proposta. In: TORRES, R. M. Educação para todos: a tarefa por fazer. Tradução: Daisy Vaz de Moraes. Porto Alegra: ARTMED, 2001, p.19-24. 